\title{
Evaluation of the Global Behaviour of Tall Reinforced Concrete Buildings Using Discrete and Continuum Approaches
}

\author{
Ali Al-Balhawi ${ }^{1}$, Binsheng Zhang $^{2}$ and Nicholas Hytiris ${ }^{3}$
}

\begin{abstract}
This paper assesses the reliability of applying a popular continuum method "Equivalent Column Theory" into investigating the static and dynamic performance of various tall reinforced concrete building systems. Analytical formulae of this method were used to explore many issues that relate to the local and global behaviours of tall buildings such as horizontal deflections and fundamental frequencies in $x$ and $y$ directions and about $z$-axis. Therefore, to confirm the accuracy of this method, the same models were simulated by using the commercial finite element software SAP2000 which is considered as an exact and reliable method for comparison.
\end{abstract}

Keywords - tall building, global behaviour, finite element method, continuum method, equivalent column

\section{Introduction}

Tall buildings have been the amazing icon of the urban development in many countries around the world. These types of buildings have complicated behaviours that are related to their bracing elements of different structural systems and applied actions. For example, the structural behaviour of various types of tall buildings under horizontal loads such as wind is very crucial, because it is related to the global stability of buildings and comfort of residents. These behaviours are very significant to be known for validating the analysis and design of tall buildings.

So far, many approximate analytical methods have been proposed for investigating the local and global behaviours of various types of structural systems of tall reinforced concrete buildings such as frameworks and frame-shear walls/cores, and they are classified depending on the continuum method and the applied assumptions for simplifying the behaviour of those buildings. These studies are illustrated in the references [1]-[8].

In this study, a popular analytical continuum method called "Equivalent Column Theory" which treats many bracing elements of a tall building as an equivalent column with respect to their stiffnesses and other characteristics will be utilised, tested and compared with the numerical method by using FEM programme SAP2000 (V.15) to evaluate the global behaviour of tall reinforced concrete buildings with respect to horizontal deflections and fundamental modal frequencies in $\mathrm{x}$ and $\mathrm{y}$ directions and about $\mathrm{z}$-axis.

\section{${ }^{1} \mathrm{PhD}$ Student}

School of Engineering and Built Environment / Glasgow Caledonian University / UK

${ }^{2}$ Senior Lecturer

${ }^{3}$ Senior Lecturer
Finite element analysis methods have been developed over the past decades for analysing and designing different types of structures under various types of loading in 2D and 3D with high accuracy. Any errors within modelling of the bracing elements and the applied assumptions and loadings, however, will lead to inaccurate structural performances of these tall buildings. For very complicated situations, it is very time consuming and hard to investigate the relative errors within enormous output data.

First, the reason for choosing "Equivalent Column Theory" is that it depends on the stiffness characteristics of different bracing elements of tall buildings in a simplified manner which is logic to follow for interpreting the predicted approximate behaviour. Another reason is that the addressed methods depend on different approaches such as the discrete and continuum methods. Thus, the similarity in the conducted behaviour results indicates that the applied methods are correct and reliable.

\section{Methodologies}

\section{A. Equivalent Column Method}

The behaviour of a multi-storey building in terms of the lateral resistance depends upon the stiffness contributions of its members and differs from one system to others based on parameters, e.g. the structural system, the plan arrangement of the bracing members (symmetrical or unsymmetrical), the relation to the position of the gravity centre of the building, the height of the building, etc. For instance, low rise buildings are dominant by shear behaviour, and medium rise buildings have interactions between the shear and bending behaviours. For tall buildings the bending behaviour is predominant due to the shortening of columns, which leads to ignorance of the shear deformation of framework. Thus, any analytical method should take into consideration the effective parameters that influence the local and global behaviour of multi-storey buildings when predicting their behaviour in a more accurate manner.

One of the approximate and most popular analytical methods is the continuum method which provides the possibility for dealing with different structural systems of multi-storey buildings, e.g. rigid fame systems and frameshear walls/cores systems by incorporating simplified assumptions and proposed parameters to predict the global behaviour of those systems in static and dynamic analyses. Based on the theory of sandwich structures, the behaviour or the deflection of a multi-storey rigid frame structure under lateral static load is divided into three major parts in terms of stiffness contributors. The first one is the shear behaviour which represents by shear stiffnesses of columns and beams, 
$K$; the second one is the global bending of the whole structure as one unit and is represented by global bending stiffness of columns, $E I_{\mathrm{g}}$; and the third one is the local bending of full height of individual columns using the local bending stiffness of columns, EI. This terminology provides the possibility for identifying the contributions of different bracing systems of multi-storey buildings to evaluate the local and global behaviours of those buildings in a simplified manner [8].

The reference [8] has used this terminology to deal with local and global behaviours of different bracing systems of multi-storey buildings through deriving the differential equations of these systems which depend on the continuum method with applying appropriate boundary conditions to represent the whole multi-storey building as an equivalent single column that has the sum of the relevant stiffnesses of its members. Hence, based on this, the contributions of other bracing elements such as shear walls/cores in the lateral resisting systems are assumed to be the local bending stiffness only in corresponding to the local bending stiffness of columns in rigid frame systems depending on the fact that their resistance to global bending and shear is very big.

The evaluation of the characteristics of different bracing elements in terms of the related stiffness provides the possibility of identifying the position of the shear centre of the whole system as an equivalent column in relation to the centroid of the building plan, which indicates the predicted behaviour of the whole system under the applied loading. If the shear centre of the equivalent column coincides with the gravity centre of the building plan (for a symmetrical arrangement) and the applied horizontal loading, the building will be subjected to translational deflections in $\mathrm{x}$ and $\mathrm{y}$ directions only and not to rotation or torsional deflection about z-axis. In the unsymmetrical building the rotation or torsional behaviour will play an important role in relation to the distance between the shear centre of the equivalent column and the gravity centre of the building plan and the applied loading.

The recent successful development of the equivalent column method to deal with the global behaviour of various structural systems of tall reinforced concrete buildings in terms of maximum horizontal deflections and fundamental frequencies in $\mathrm{x}$ and $\mathrm{y}$ directions and about $\mathrm{z}$-axis will be used in this study. For global analysis of multi-storey buildings of different bracing elements regarding lateral deflection, the development takes into account the interaction between all bracing elements of one system based on the base unit that depends on the largest shear contributor of the system, e.g. rigid frame. Therefore, each bracing element will take the applied loading in proportion to its stiffness. Regarding the fundamental frequencies in dynamic analysis, the shear is combined together with local and global bending stiffnesses of the whole system through the effective shear stiffness and the local bending stiffness to form the single equivalent column. The relevant derived formulae are based on the following assumptions [8]:

- The building should be at least four storeys with identical storey heights;

- The characteristics of the members should be uniform throughout the height, i.e. having constant stiffness throughout the height;

- The structure is fixed at base and free at top;
- The floor slabs are assumed rigid in their planes;

- The mass of the building is assumed to be uniformly distributed over the building height;

- The location of the shear centre only depends on geometrical characteristics;

- The material of the structure is assumed to be linearly elastic;

- The loads are applied uniformly and statically;

- The P-delta effects are negligible.

The analytical formulae for evaluating the global behaviour of different structural systems of tall buildings are adopted from [8] as follows.

- The coordinates for the shear centre of the single equivalent column, $\bar{x}_{0}$ and $\bar{y}_{0}$, can be determined from (1):

$$
\bar{x}_{0}=\frac{\sum_{1}^{f+m} I_{\mathrm{x}, \mathrm{i}} \bar{x}_{\mathrm{i}}}{\sum_{1}^{f+m} I_{\mathrm{x}, \mathrm{i}}} \quad \text { and } \quad \bar{y}_{0}=\frac{\sum_{1}^{f+m} I_{\mathrm{y}, \mathrm{i}} \bar{y}_{\mathrm{i}}}{\sum_{1}^{f+m} I_{\mathrm{y}, \mathrm{i}}}
$$

where $f$ and $m$ are the numbers of frames and shear walls/ cores, $I_{\mathrm{x}, \mathrm{i}}$ and $I_{\mathrm{y}, \mathrm{i}}$ are the second moments of inertia for bracing element $i$, and $\bar{x}_{i}$ and $\bar{y}_{i}$ are the perpendicular distances to the shear centre for element $i$, in relation to the coordinate system for the building plan.

- The maximum deflection $y(H)$ for the frame system at the full height $H$ can be obtained by letting $z=H$ in (2):

$$
\begin{aligned}
& y(z)=\frac{w}{E I_{\mathrm{f}}}\left(\frac{H^{3} z}{6}-\frac{z^{4}}{24}\right)+\frac{w z^{2}}{2 K s^{2}} \\
& -\frac{w E I}{K^{2} s^{3}}\left(\frac{\cosh [\kappa(H-z)]+\kappa H \sinh (\kappa z)}{\cosh (\kappa H)}-1\right)
\end{aligned}
$$

- The maximum deflection $y(H)$ for the shear walls/cores at the full height $H$ can be calculated by letting $z$ $=H$ in $(3)$ :

$$
y(z)=\frac{w}{E I}\left(\frac{H^{3} z}{6}-\frac{z^{4}}{24}\right)
$$

- The maximum deflection $y(H)$ for the frame-shear wall/core system at the full height $H$ can be calculated by using the unit base procedure from (4):

$$
y(H)=\frac{\bar{w} H^{4}}{8 E I_{\mathrm{f}}}+\frac{\bar{w} H^{2}}{2 K \bar{s}^{2}}-\frac{\bar{w} E I}{K^{2} \bar{s}^{3}}\left(\frac{1+\bar{\kappa} H \sinh (\bar{\kappa} H)}{\cosh (\bar{\kappa} H)}-1\right)
$$

where $\bar{w}$ is the load share of the base unit, $E I_{\mathrm{f}}$ and $E I$ are the global and local bending stiffnesses of the base unit, $K$ is the shear stiffness of the base unit, and $\bar{s}$ and $\bar{\kappa}$ the stiffnesses parameters of the whole system.

- The lateral frequencies of the whole system regarded as a single equivalent column in $\mathrm{x}$ and $\mathrm{y}$ directions, $f_{\mathrm{x}}$ and $f_{\mathrm{y}}$, can be calculated from (5): 


$$
f_{\mathrm{x}, \mathrm{y}}=\sqrt{f_{\mathrm{b}}^{2}+f_{\mathrm{s}}^{2}+\left(\frac{\eta^{2}}{0.313}-\frac{k^{2}}{5}-1\right) s_{\mathrm{f}} f_{\mathrm{b}}^{2}}
$$

where $f_{\mathrm{b}}$ and $f_{\mathrm{s}}$ are the bending and shear stiffnesses of the single equivalent column, $\eta$ and $k$ are the frequency parameters, and $s_{\mathrm{f}}$ is the shear effectiveness factor for the equivalent column.

- The torsional frequency of the single equivalent column about z-axis, $f_{\phi}$, can be calculated from (6):

$$
f_{\phi}=\sqrt{f_{\omega}^{2}+f_{\mathrm{t}}^{2}+\left(\frac{\eta_{\phi}^{2}}{0.313}-\frac{k_{\phi}^{2}}{5}-1\right) s_{\phi} f_{\omega}^{2}}
$$

where $f_{\omega}$ and $f_{\mathrm{t}}$ are the pure torsional frequencies of the warping and Saint-Venant torsional stiffnesses of the single equivalent column, $\eta_{\varphi}$ and $k_{\varphi}$ are the torsional frequency parameters, and $s_{\varphi}$ is the effectiveness factor of the SaintVenant torsional stiffness of the single equivalent column. The relevant parameters and their tabulated values can be found in [8]. The mass of floor slabs are also included in the frequency terms.

\section{B. Finite Element Method (FEM)}

FEM has been developed over the past two decades to analyse and design various types of buildings in $2 \mathrm{D}$ and $3 \mathrm{D}$ taking into account the simplicity and complexity of the involved members. The accuracy of models depends on the applied assumptions varying between structures and also on the consumed time and capacity of handling massive data. In many cases, the increasing complexity of modelling assumptions such as using very fine mesh does not mean getting more accurate results. In contrast it may increase the errors with inaccurate results.

FEM regards as discrete method because it takes the whole system into consideration in 3D analysis, in which it provides the interaction between different bracing elements in spatial behaviour. Therefore, using simplified analytical method which based on continuum approach, the conducted behaviour will provide the possibility of identifying any error within the applied assumptions of FEM, in which it is very difficult to trace the error in the FEM models due to the enormous amount of input and output data [9].

In this study, the FEM software SAP2000 (V.15) was used for modelling three types of tall reinforced concrete buildings by applying various assumptions, e.g. the bare frame, rigid diaphragm for floor slabs, shell elements for floor slabs and shear walls/core, coarse and fine meshes for floor slabs and shear walls/core to reflect their effects on the global behaviour of multi-storey reinforced concrete buildings, etc. Similarly, the same models were analysed by using the analytical continuum method which was explained in more details in the previous sub-section.

\section{Numerical Examples}

In this section, the explained methods were employed for analysing three structural systems of tall reinforced concrete buildings including rigid frame system, frame-shear wall system, and frame with central core (tube) system subjected to uniformly distributed static horizontal wind loads in $\mathrm{x}$ and y directions and the results will be compared to verify the predicted responses of the models. For the continuum method, the analytical formulae were implemented in Mathcad program to predict the maximum horizontal deflections and fundamental frequencies in $\mathrm{x}$ and $\mathrm{y}$ directions and about $\mathrm{z}$-axis for the tall buildings studied.

Three typical building systems with three different heights say 10,20 and 30 storeys were analysed. The applied static horizontal wind loads were $5 \mathrm{kN} / \mathrm{m}^{2}$ in the $\mathrm{x}$ and $y$ directions, the elastic modulus of $\mathrm{C} 25 / 30$ concrete is $31 \times 10^{6} \mathrm{kN} / \mathrm{m}^{2}$ and the shear modulus of elasticity is $12.92 \times 10^{6} \mathrm{kN} / \mathrm{m}^{2}$. The dimensions of the proposed structural members are listed in Table 1 . The weight per unit volume of the buildings for dynamic analysis ranges from 0.86 to $2.5 \mathrm{kN} / \mathrm{m}^{3}$. The floor plans for the structural systems are shown in Fig.1. The obtained results of the addressed models using two methods will be stated in the next section.

TABLE 1 GEOMETRIC PROPERTIES OF STRUCTURAL MEMBERS OF FRAMESHEAR WALLS/CORES

\begin{tabular}{|l|c|c|}
\hline \multicolumn{1}{|c|}{ Sections } & Depth $(\mathbf{m})$ & Width $(\mathbf{m})$ \\
\hline Beams & 0.6 & 0.4 \\
\hline Columns & 0.4 & 0.4 \\
\hline Shear walls/cores & 0.3 & 4 \\
\hline Slabs & 0.2 & - \\
\hline
\end{tabular}
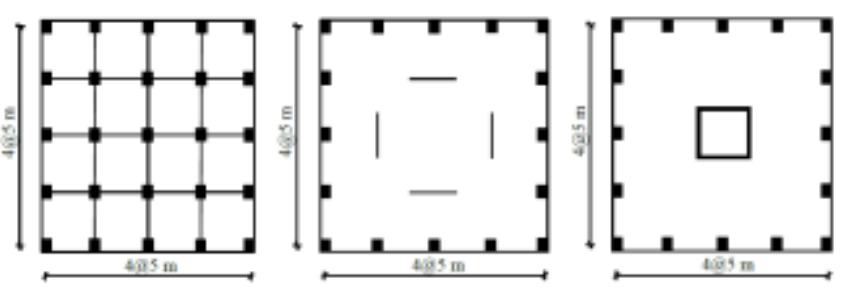

Figure 1. Floor plans of three typical multi-storey buildings

\section{Results and Discussion}

This section includes the obtained analytical results of the addressed models by using FEM and the equivalent column method. The static analysis of the global behaviour of the models regarding the translational deflections in $\mathrm{x}$ and y directions resulting from the applied horizontal static loads is shown in Figs. 2, 3 and 4, respectively.

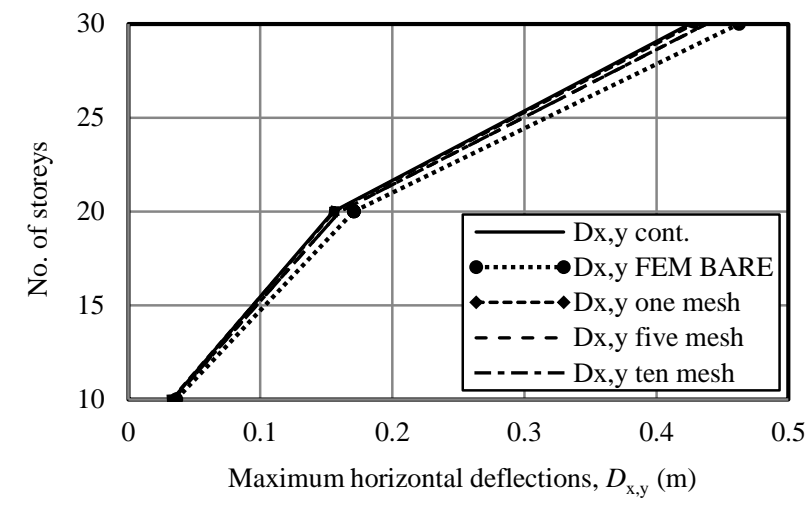

Figure 2. Maximum horizontal deflections, $D_{\mathrm{x}, \mathrm{y}}$, of the frame system of different storeys 


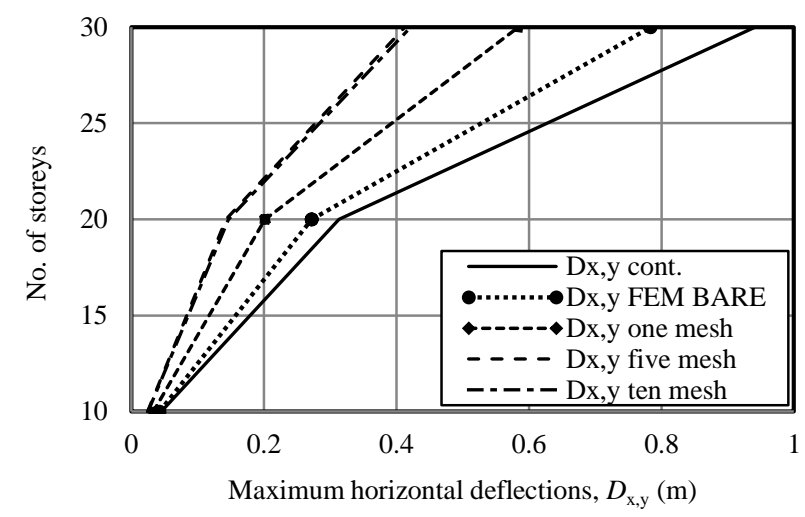

Figure 3. Maximum horizontal deflections, $D_{\mathrm{x}, \mathrm{y}}$, of the frame-shear walls system of different storeys

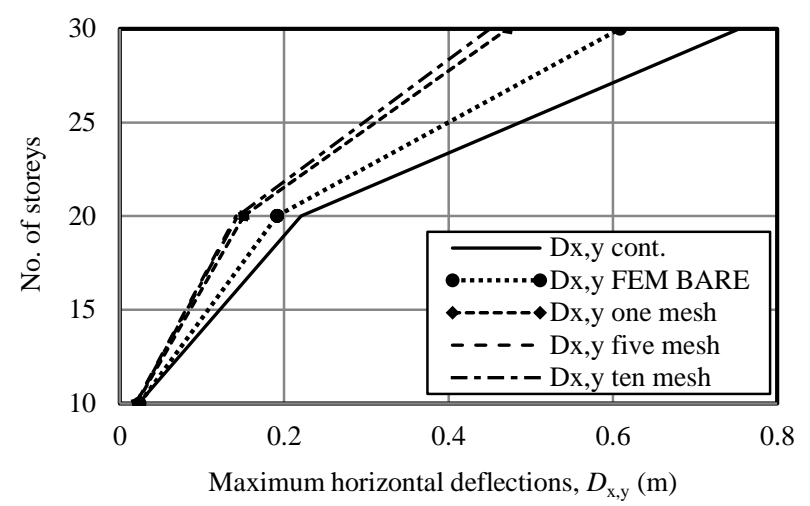

Figure 4. Maximum horizontal deflections, $D_{\mathrm{x}, \mathrm{y}}$, of the frame-central core system of different storeys

For the maximum horizontal deflections of the frame system of different storeys, it can be seen that in Fig. 2 a very good agreement between the results obtained by the two methods. Despite of using different modelling assumptions in FEM, the continuum method has the ability to capture the global behaviour of the frame system in terms of maximum horizontal deflections in $\mathrm{x}$ and $\mathrm{y}$ directions.

In Fig.3, the situation is different in comparison with the frame system due to the contributions of slab flexural stiffness toward the shear walls through refining the mesh for floor slabs and shear walls. The bare frame assumption of ignoring the flexural stiffness of floor slabs and using the rigid floor diaphragm to ensure a unique deflection for all bracing elements will make the deflections closer to those using the continuum method. These differences between the two methods are caused by the ignorance of the flexural stiffness of floor slabs by assuming the rigid diaphragm of the floor slabs only in the continuum method.

In Fig.4 the same trends are observed in the framecentral core system due to the contribution of the flexural stiffness of floor slabs to the central core, which decreases the horizontal deflections in $\mathrm{x}$ and $\mathrm{y}$ directions. However, the results did not change largely when refining the floor slab mesh in comparison with the same mesh for the frameshear walls system. The results for the continuum method regarding the maximum deflections are very conservative (overestimated) in comparison with the FEM results.

For the dynamic analysis using the addressed models with respect to the fundamental frequencies for the first modes in two principal $\mathrm{x}$ and $\mathrm{y}$ directions and about $\mathrm{z}$, are shown in Figs. 5 to 10, respectively.

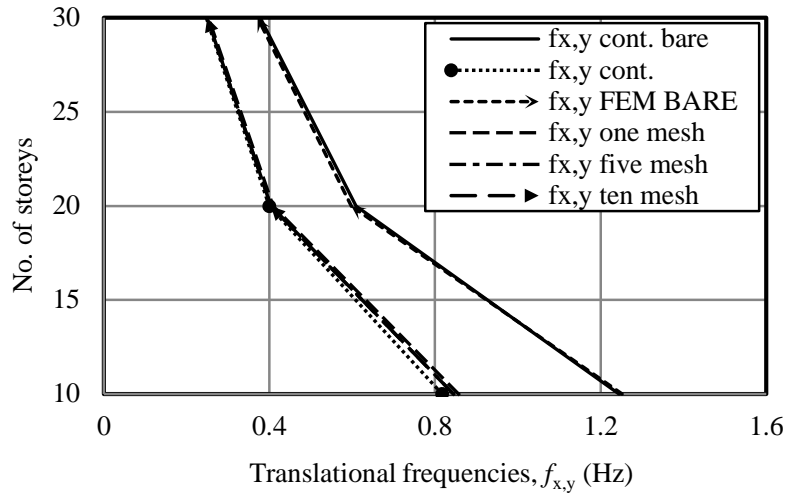

Figure 5. Translational fundamental frequencies, $f_{\mathrm{x}, \mathrm{y}}$, of the frame system of different storeys

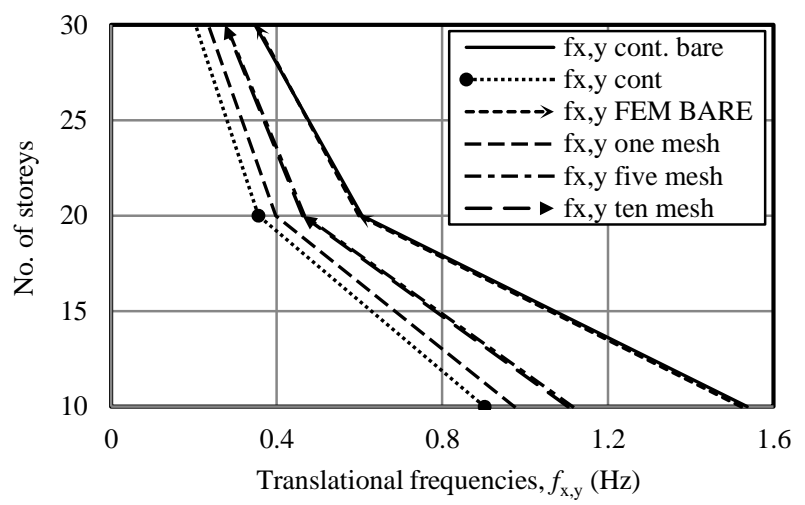

Figure 6. Translational fundamental frequencies, $f_{\mathrm{x}, \mathrm{y}}$, of the frame-shear walls system of different storeys

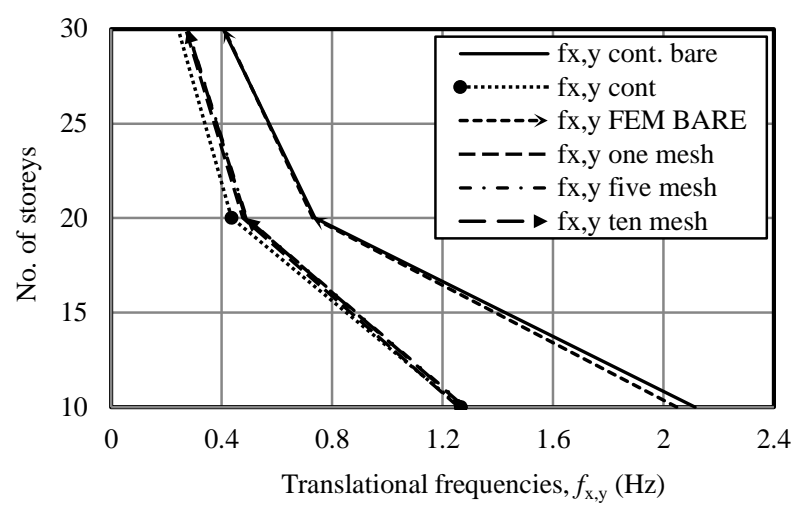

Figure 7. Translation fundamental frequencies, $f_{\mathrm{x}, \mathrm{y}}$ of the frame-central core system of different storeys

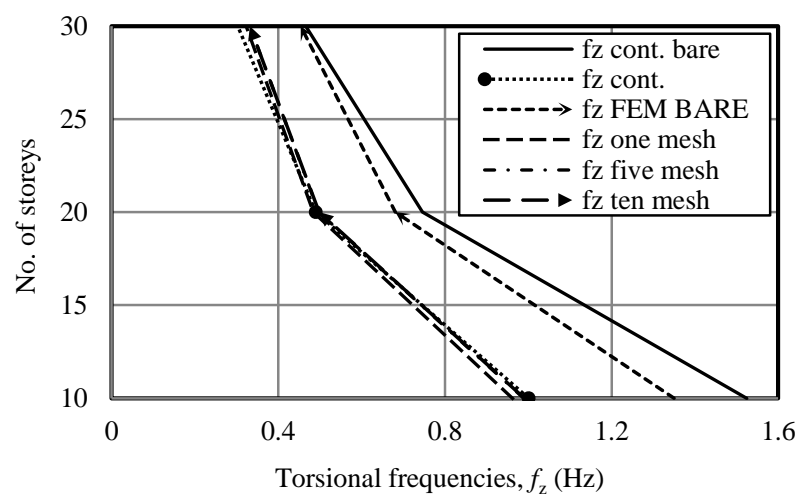

Figure 8. Torsional fundamental frequencies, $f_{\mathrm{z}}$, of the frame system of different storeys 


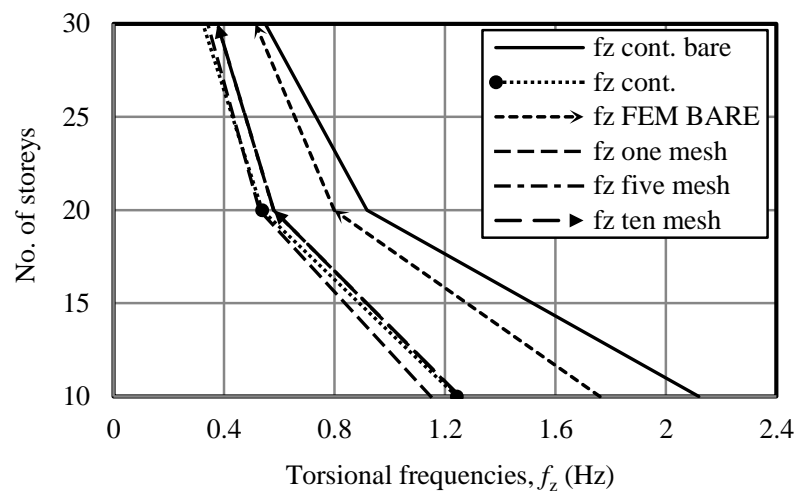

Figure 9. Torsional fundamental frequencies, $f_{\mathrm{z}}$, of the frame-shear walls system of different storeys

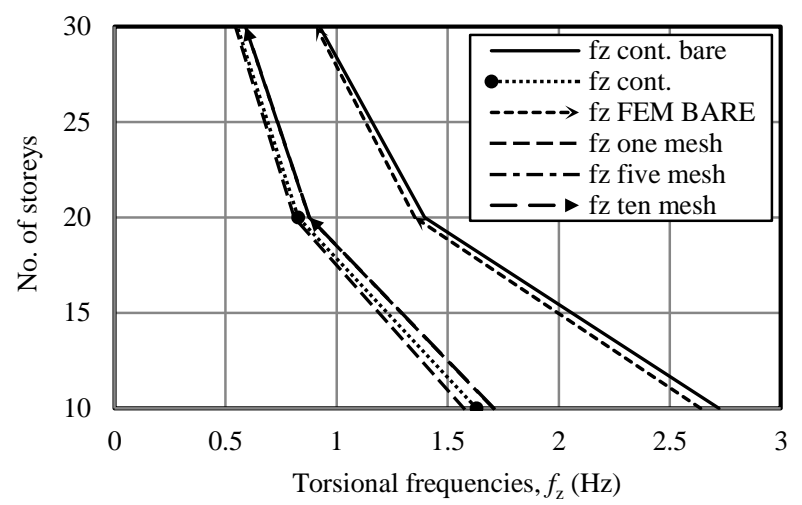

Figure 10. Torsional fundamental frequencies, $f_{\mathrm{z}}$, of the frame-central core system of different storeys

In general, the calculated fundamental frequencies in two principal $\mathrm{x}$ and $\mathrm{y}$ directions and about $\mathrm{z}$-axis indicate a very good agreement between the FEM and the equivalent column method due to the inclusion of the floor mass into the analytical formulae for calculating the fundamental frequencies of bending and torsional modes.

The fundamental frequencies in the translational $\mathrm{x}$ and $\mathrm{y}$ directions for the first modes of the frame system show a very good agreement between the two methods. However, the situation is different in the frame-shear walls system due to the contribution of the flexural stiffness of floor slabs toward the relevant stiffness of the shear walls and the singularity of the open section of shear walls. In contrast to the frame-shear walls system, the frame-central core system showed the same trend as the frame system in terms of the fundamental frequencies in $\mathrm{x}$ and $\mathrm{y}$ directions due to higher stiffness of the closed section of the central core compared with the open sections of shear walls.

Regarding the torsional frequencies for the first mode, the continuum method indicated a very good agreement in comparison with the FEM simulations due to the inclusion of the floor mass, torsional stiffness and other parameters in the analytical formulae and would provide the opportunity to capture the global torsional behaviour of different structural systems. In addition, using finer element mesh showed an influence on the torsional behaviour of the multi-storey buildings by increasing the torsional frequency. This made the torsional frequencies obtained from the continuum method marginally underestimated, which means to be slightly more conservative. It is worthwhile to indicate that even though the floor slab was deliberately ignored by applying the rigid floor diaphragm constraint assumption in the FEM simulations of the three systems, the continuum method is still providing good results in comparison with the FEM results.

Finally, in terms of the fundamental frequencies, the accuracy of the equivalent column method increased with the increasing storey number of the buildings for all three systems studied, while for the maximum deflections of the frame-shear walls/core systems the accuracy decreased with the increasing storey number of the buildings. In addition, there was no coupling between the bending and torsional modes due to the symmetrical building plan arrangements.

\section{v. Conclusion}

It has been shown that the employment of different approaches for analysing multi-storey buildings is beneficial for comparing the conducted results and verifying the global behaviour of these buildings. The analytical equivalent column method can be used for the analysis on multi-storey buildings due to its good agreement with the FEM regarding the fundamental frequencies. However, use the same method would overestimate the maximum deflections due to the ignorance of the contributions of the flexural stiffness of floor slabs toward the shear walls and cores for the frameshear walls/cores systems.

\section{Acknowledgment}

This study was supported under the scholarship (20142017) funded by the Higher Committee for Education Development, The Prime Minister Office of Iraq.

\section{References}

[1] I. A. Macleod, "Simplified analysis for shear wall-frame interaction," Build. Sci., vol. 7, no. 2, pp. 121-125, 1972.

[2] A. Coull, B. S. Smith, and B. Smith, "Structural analysis of tall concrete buildings," Proc. Inst. Civ. Eng., vol. 55, no. 1, pp. 151-166, Mar. 1973.

[3] B. S. Smith and D. P. Abergel, "Approximate analysis of high-rise structures comprising coupled walls and shear walls," Build. Environ., vol. 18, no. 1-2, pp. 91-96, 1983.

[4] B. S. Smith and A. Coull, Tall Building Structures: Analysis and Design, John Wiley \& Sons, US, 1991.

[5] K. A. Zalka, Global Structural Analysis of Buildings, E \& FN Spon, London, UK, 2000.

[6] K. A. Zalka, "A simplified method for calculation of the natural frequencies of wall-frame buildings," Eng. Struct., vol. 23, no. 12, pp. 1544-1555, 2001.

[7] K. A. Zalka, "A simple method for the deflection analysis of tall wallframe building structures under horizontal load," Struct. Des. Tall Spec. Build., vol. 18, no. 3, pp. 291-311, 2009.

[8] K. A. ZalKa, Structural Analysis of Regular Multi-Storey Buildings, CRC Press, Boca Raton, US, 2012.

[9] I. A. MacLeod, Analytical Modelling of Structural Systems: An Entirely New Approach with Emphasis on Behaviour of Building Structures, Ellis Horwood Ltd, Sothampton, UK, 1990.

About Author (s):

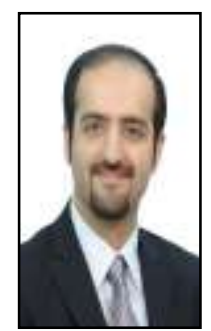

Ali was working as an assistant lecture of the Civil Engineering Department in the College of Engineering at the University of Al-Mustansiriya Baghdad, Iraq. He has been pursuing a $\mathrm{PhD}$ in Civil Engineering at Glasgow Caledonian University, Scotland, UK, since 2014. 